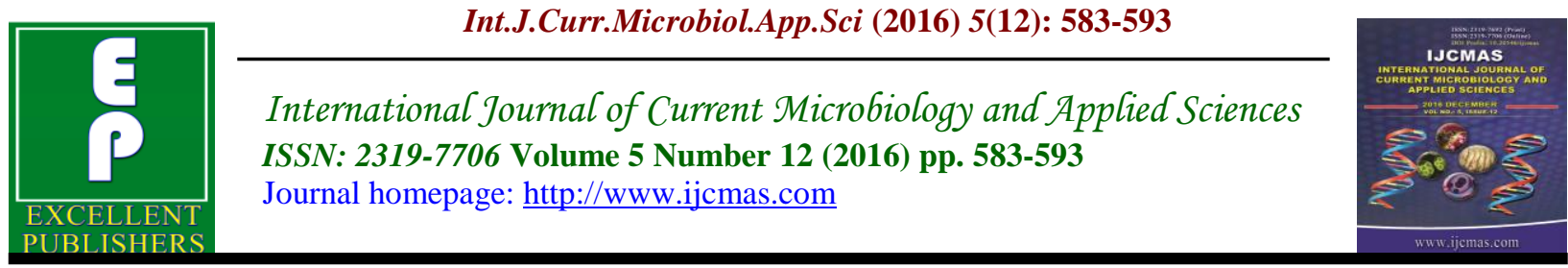

Original Research Article

http://dx.doi.org/10.20546/ijcmas.2016.512.063

\title{
Participation of an Inactive and Active Src-kinase in Formation of a Cytoskeleton and Melanogenesis in Hep2 Cells
}

\author{
Tatiana Yavisheva* and Sergey Shcherbakov \\ Joint Stock Company "R-PHARM”, Moscow, Russian Federation \\ *Corresponding author
}

A B S T R A C T

Keywords

Active and inactive

Src-kinase,

cytoskeleton

formation,

melanogenesis.

\section{Article Info}

Accepted:

18 November 2016

Available Online:

10 December 2016
The present study investigated the participation of an inactive and active Src-kinase in the functions of cytoskeleton and pigment formation inHep2 cells. For increase of the inactive portion of the Src-kinase and decrease of its active part we entered specific Src-kinase family inhibitor CGP 77675 into cell population. For the decrease of the inactive portion of Src-kinase, the tumor cells were affected by ultraviolet (UV) radiation within 5, 30 and 60 minutes. We studied the dynamics of the quantity of cells with processes and also the cells with tyrosinase activity. It appeared that only the inactive Src-kinase participates in cytoskeleton formation and in tyrosinase activization. Strengthening of melanogenesis during long UVradiation within 30 and 60 minutes reduced the portion of the inactive Src-kinase due to the intensification of tyrosinase synthesis. The last in turn began to compete with a cytoskeleton for the inactive Src-kinase that reduced a differentiation of cells and sharply worsened a phenotype of tumor cells.

\section{Introduction}

We revealed earlier that proliferation and differentiation of cells is carried out in the morphofunctional zones consisting of two subunits with 12 cambial cells in each. Nonreceptor Src-kinase is one of the key proteins participating in these processes (Yavisheva et al., 2009; Yavisheva et al., 2005).Thus, 12pairs of mother and daughter cells are formed during the division of cambial cells in one subunit. They generate the electric field due to the difference of the superficial charges between these cells (Yavisheva et al., 2007). The electric field stretches a body of a daughter cell that demands the increase of a cell wall sizes. In this regard, the exocytose bubbles split off from membranes of an endoplasmic reticulum, in which the Src-kinase occurs, i.e. stretching induces intensive synthesis of the Src in daughter cells. The Src-kinase participates in the formation of a cell cytoskeleton: microtubules, intermediate filaments, which provide stretching of the daughter cell nucleus and untwisting of certain loci of chromosomes, leading to a cell differentiation. Then the daughter cells as the earliest offspring of the cambial cells gradually pass into narrow cells which further mature into oval cells. The latters fill up the reserve cells which represent the depot of cells for layer regeneration. The reserve cells during regeneration pass in turn 
into transitional and elongated cells. The last directly enter into mitosis and further mature to final cells. Interestingly, that at the moment of the daughter cell stretching in the electric field there is not only cytoskeleton formation, but also an activization of tyrosinase activity of a cell occurs (Yavisheva et al., 2012). Therefore, the Srckinase participates simultaneously in cytoskeleton construction and activization of daughter cell tyrosinase. These two functions are very important in the cell, because the change of one of them leads to violations of the another.

The Src-kinase represents large allosteric enzyme which can be exposed to conformational changes depending on extracellular or intracellular signals. At the same time enzyme gets an active or inactive state (Sichun et al., 2008).. In the active state the Src-kinase phosphorylates manyproteins participating in proliferative process and also protein p190RhoGAP which inactivates RhoA (one of small Gproteins). The latter participates in regulation of actincytoskeleton (Arthur et al., 2000; Brunton et al., 2004). Therefore the research aim was to reveal in what state (active or inactive) the Src-kinase participates in functions of a cytoskeleton formation and melanogenesis and how the proportion between an active and inactive Src-kinase can influence on these functions. For this purpose we strengthened the activity of the Src-kinase by means of UV-radiation of Hep2 cells and investigated a cytoskeleton and melanogenesis in cells. The quantity of the inactive Src-kinase was increased due to entering of Src-kinase inhibitor.

\section{Materials and Methods}

Cultivation of cells: For studying of the active and inactive Src-kinase participation in processes of cytoskeleton formation and melanogenesis we used the human Hep2 carcinoma cells. Cells were cultivated in DMEM (Paneco, Moscow) containing 10\% fetal bovine serum (FBS) (Biosera, France), $200 \mathrm{mM}$ L-glutamin and $50 \mu \mathrm{g} / \mathrm{ml}$ gentamycin.. The cells were incubated in cell culture flasks $25 \mathrm{~cm}^{2}$ in area at $37{ }^{\circ} \mathrm{C}$ in the atmosphere of $5 \% \mathrm{CO} 2$. When the confluent condition was reached, the cells were transferred on standard slides. Slides with the cells were placed in sterile Petri dishes with DMEM of the above-mentioned composition, stored in stove at $37^{\circ} \mathrm{Cuntil}$ they reach a subconfluent state.

For suppression of the Src-kinase activity the Src-kinase family inhibitor CGP 77675 was added in 3 dishes with cells in DMEM in concentration $1 \mathrm{mM}$ at $37^{\circ} \mathrm{C}$.

For the purpose of the Src-kinase activation other 3 dishes with the cells were radiated with an ultra-violet lamp within 5, 30 and 60 minutes with the further incubations at $37^{\circ}$ $\mathrm{C}$ in the atmosphere of $5 \% \mathrm{CO} 2$. We used two bactericidal lamps (Philips, special TUV 301).

The next day the slides with the cells were washed twice in PBS and fixed in 10\% formalin within 20 minutes. Then we prepared the received material by the following techniques. In one part of preparations we defined tyrosinase activity of cells. For this, slides with the cells were placed in incubatory solution (0,3\% DOPA + the phosphatic buffer) at $37^{\circ} \mathrm{C}$ for 3 hours. Brown-black colored granules pointed to the contents of tyrosinase in cells. For definition of pigment function of cells we counted the quantity of the cells with tyrosinase activity without processes; and for the purpose of studying of a cytoskeleton formation we counted the quantity of cells with processes, having tyrosinase activity, in 25 visual fields (Ob.x40, Oc.x10) and then determined average value of each parameter. 
The same cells without any actions were used as control. The obtained data processed statistically with use of nonparametric criterion of Wilcoxon-Mann-Whitney (Gubler et al., 1973).

Other part of preparations was stained with Mayer's haematoxylin with in 1 minute for a morphofunctional research of tumor cells population by the method of the automated morphometry. The analysis was carried out on the image analyzer ("MultiMeter", Russia). Studying of the intensively proliferating populations of cells was carried out on histograms of cells distribution with respect to their degree of ellipticity (DE) by the method, developed by us (the patent in process). The series of cells were formed of classes in such a way that all classes within the same series were very close to each other due to their percentage. The series were called according to the DE of cells (Yavisheva et al., 1996).

Narrow cells are one of the earliest offspring of cambial cells with the smallest values of DE from 0, 1077 to 0, 2615. These cells gradually pass into oval with DE from 0,6124 to 0,7846 . The last transform into the reserve cells, filling up their depot.

Reserve cells (DE 0, 5774) occupy the greatest percent among all the cells and are a peculiar depot on population regeneration.. During the increase of proliferative activity these cells gradually pass into transitional (DE 0,4154-0,5692) and then into elongated cells (DE from 0,2615 to 0,4154).The elongated cells directly enter into mitosis. On reaching $30 \%$ there is a jump, i.e. a part $(5 \%)$ of these cells synchronously enter into mitosis. As a result round cells which mature further to final cells turn out.

Besides, for comparison of area change of the cells under various influences we measured this parameter in pixels.
In each concrete case we investigated 2-3 thousand of cells. The quantity of cambial cells we measured by the number of narrow cells, because cambial cells have very short synthetic period that complicates their calculation by the method of the automated morphometry.

\section{Results and Discussion}

It is shown above that the daughter cell during stretching in the electric field passes through the stage of cytoskeleton formation and tyrosinase activization. We observed such picture not only in skin epidermis, but also in eye cornea anterior epithelium, in intestinal epithelium and other epithelia (Yavisheva et al., 2013). Because the tyrosinase activity is characteristic for the earliest offspring of cambial cells, it can influence on cytoskeleton formation.

Two series of experiments were carried out for the purpose of decrease or increase of the inactive Src-kinase portion inthe cells and identification of correlation between functions of cytoskeleton formation and melanogenesis, because we showed earlier that inactive Src-kinase takes part in both of these processes (Yavisheva et al., 2014).

We calculated the quantity of cells, which have the tyrosinase activity, but do not have processes, for the purpose of studying of melanogenesisin cells (further: the cells without processes); the cells with tyrosinase activity, which have processes - for a cytoskeleton research (further: cells with processes), and also total quantity of cells with tyrosinase activity. It is known that microtubules and microfilaments are an obligatory component of processes (Chentsov, 2005). Therefore the quantity of cells with processes can demonstrate the extent of cytoskeleton formation of cells. 
In the first series of experiments we reduced a portion of the inactive Src-kinase in cells, and in these conditions investigated the state of cytoskeleton and the influence of tyrosinase activity on its formation. For this purpose the Hep2 cell population was subjected to ultra-violet radiation (UV) within 5, 30 and 60 minutes.

At influence on a cellular membrane UV initiates an oxidative stress and formation of active forms of oxygen (Netrunenko et al., 2007). It is known that the Src-kinase is the redox-sensitive molecule which actively reacts to action of the extracellular oxidants and different stresses: UV, an inflammation, an oxidative stress, etc. (Aikawa et al, 1997; Burova et al., 2003; Devary et al., 1992). Thyolgroups, being a part of the Src-kinase, are oxidizede asily, thus the spatial configuration of a molecule changes, that leads to activization of its kinase domain (Mallozzi et al., 2001). Therefore, the part of the inactive Src-kinase in the cell will fall at UV-radiation.

The research revealed, that after 5-minute UV-radiation the number of the cells with processes raises to 1,35 cells in comparison with control (0,95 cells), and the total quantity of cells with tyrosinase activity decreases to 5,6 cells (in control 7,35 cells) (table 1, fig. 1).

However at increase of UV exposition time up to 30 and 60 minutes the accurate tendency of decrease in quantity of cells with processes was noted. If in control their number compounded $0,95 \mathrm{cells}$, then at 30 minutes of UV-radiation - 0,4 cells, and at 60 minutes - only 0,2 cells. Along with it the total quantity of cells with tyrosinase activity continued to fall and at 30 minutes compounded 4,3cells, and 60 minutes $-3,3$ cells (in control $-7,35$ cells).
Thus, the quantity of the cells with processes in control compounded $12,9 \%$ of total number of cells with tyrosinase activity. At 5-minutes UV-radiation the number of the cells with processes sharply increased and reached $24.1 \%$. Further at radiation within 30 minutes their quantity was strongly reduced to $9,3 \%$, at 60 minutes - to $6,1 \%$ of total number of cells with tyrosinase activity. Therefore, the greatest fluctuations in quantity of cells with processes happened at 5 and 30 minutes of radiation. And, at 5minute of UV, the increase in portion of the cells with processes was followed by reduction of cells without processes. The opposite picture was observed at 30 minutes of radiation: at decrease in portion of the cells with processes, the increase of cells without processes occurs.

It is shown above that UV, as an oxidant, increases the activity of the kinase domain of Src and reduces a part of inactive Src which is used for a cytoskeleton construction and tyrosinase activization. At 5-minutes UV-radiation the reduction of the part of the inactive Src-kinase caused compensatory strengthening of a cytoskeleton formation due to decrease of the tyrosinase activity.

We revealed earlier, that strengthening of a cytoskeleton formation leads to increase in cell stretching and additional synthesis of an inactive Src-kinase in cells (Yavisheva et al., 2013). In this regard the portion of the active Src-kinase will be small among the total enzyme. Therefore it will lead to a weak expression of protein p190RhoGAP which won't be able to reduce the RhoA activity. As a result the spasm of cells will amplify and proliferative activity of cells will decrease. So, the next days after 5minutes radiation the reduction of the cells area to 32,3 pix was noted (in control - 41,2 pix). In connection with decrease in 
proliferative activity, the density of cells at 5-minutesof radiation sharply dropped: the cells grew in the separate centers, merging only in some sites.

The next day in control the confluent growth of tumor cells was observed. Decrease in proliferative activity of cells led to reduction of cambial cells quantity in tumor tissue. Falling in number of narrow cells which are the earliest offspring of cambial cells to 6 , $9 \%$ in comparison with control $(9,3 \%)$ testifies to it. At the same time there was no accelerated transition of narrow cells into oval, because in control and at UV their number is almost identical (21, 0-21,6\%) (fig. 2).

Therefore, short, within 5 minutes UVradiation at first led to decrease in portion of an inactive Src-kinase, that caused strengthening of a cytoskeleton formation due to decrease of the tyrosinase activity. But then the inactive part of Src-kinase increases, that leads to the spasm of cells, decrease in proliferative activity of all the cells, including cambial that aggravated malignant process.

At longer influences (30 and 60 minutes) the ratio between both functions: cytoskeleton formation and melanogenesis, had other character. On the background of the decrease in total of cells with tyrosinase activity (to 4,3 at 30 minutes of UV and to 3,3 at 60 minutes of UV; in control $-7,35$ cells) raising of the part of cells without processes was noted. So at 30 minutes of radiation their portion increased to $90,7 \%$, and the cells with processes decreased to $9,3 \%$ (in control respectively 87,1 and $12,9 \%$ ). At 60 minutes of UV-radiation the percent of cells without processes compounded $93,9 \%$, and the cells with processes $-6,1 \%$.
It is known that at increase in UV exposition time and dose there is an accelerated transition of uncolored predecessors of melanin into the colored forms (Borshchevskaya et al., 1999; Netrunenko et al., 2007). It strengthens formation of DOPA and DOPA-quinone from a tyrosine by the principle of feedback that demands the increase of tyrosinase synthesis. The increased quantity of tyrosinase will compete with a cytoskeleton for the inactive Src-kinase with the purpose for its activation, that will cause decrease in a cytoskeleton formation and a differentiation.

Really, the tyrosinase is inactive and can't oxidize tyrosine if the copper cations entering into its active center are in the oxidized form (Riley, 1993).Ions of copper are capable to an oxi-reduction and participate in oxidation-reduction processes. At the same time the reactions of substratum oxidation are accelerated by oxygen. Reduction of these ions can happen due to thiol groups of the proteins which are in the melanosomes. One of donors of nucleophilic groups is the Src-kinase which was found in the melanosomes as in the active state, and also in new-synthesized. The Src-kinase can be the donor of the thiols only in the inactive state, because $\mathrm{SH}$ groups in the active state of the Src are oxidized by the different oxidants.

Therefore, activation of a large number of new-synthesized tyrosinase is followed by significant increase in the portion of active Src-kinase and decrease in inactive. At the same time the rest part of the inactive Srckinase is distributed between a cytoskeleton and melanogenesis. Therefore, despite strengthening of tyrosinase synthesis in cells at long UV-radiation, the quantity of cells with tyrosinase activity continues to fall. 
Increase in a portion of the active Src-kinase at 30-and 60-minutesof UV-radiation due to activization of tyrosinase synthesis leads to increase in cells density. So, the next day after 30-minutes UV it began to increase, and after 60 minutes of radiation the cells layer reached a subconfluent state. It is connected with the fact that the active Srckinase reduces RhoA protein expression. Therefore the spasm of cells is expressed to a lesser extent here, than at 5-minutesof radiation that doesn't protect the proliferative activity of cells (fig. 3).

Extension of the cells area to 35 pix at increase of UV exposition time (30 and 60 minutes) in comparison with 32,3 pix at 5minutesof radiation testifies to it. As a result at 30 and 60 minutes of radiation the number of the narrow cells which are the indicator of cambial cells existence came close to control (in experiment: $10,6 \%$ at 30 minutes, 9,2\% at 60 minutes; in control: 9,3\%) (fig. 2).

Along with this, at all three doses of radiation $(5,30,60$ minutes $)$ the decrease in the rate of the transforming of the reserve cells off spring was observed. Thus, at UVradiation within 5, 30 and 60 minutes the number of transitional cells compounded $26,0-28,6 \%$, and in control $-24,7 \%$. At the same time the number of the elongated cells differed from control $(25,1 \%)$ only a little and was $25,1-26,6 \%$. It demonstrates that at influence of all doses of UV on tumor cells, the transforming of the transitional cells into elongated is slowed down, i.e. the way of maturing of cells suffers that aggravates malignant process. At the same time only at 30 and 60 minutes of radiation decrease in oval cells quantity to $19,1-20,0$ was noted (in control 21,6), i.e. there was a delay of transition of narrow cells into oval. Therefore, at longer radiation within 30 and 60 minutes unlike short-term, violation of processes of cells differentiation happens at the earliest stages of cambial cells proliferation. Thus, at short and longer UVradiation two different mechanisms, directed to decrease in the inactive Src-kinase in cells, operate. At short UV-radiation decrease happens directly due to oxidizing properties of UV, at increase in UV exposition time - due to the strengthening of tyrosinase synthesis.

In the second series of experiments we increased a part of the inactive Src-kinase by means of entering of CGP 77675 inhibitor in Hep 2 cells. It blocks the ATP site in the Srckinase molecule and thus reduces the activity of its kinase domain (Breitenlechner et al., 2005).

The research showed that the quantity of the cells with processes increased to 2,6 cells in comparison with control (0,95 cells). Besides, the total number of cells with tyrosinase activity increased to 8,5 cells (in control without inhibitor $-7,35$ cells) (fig. 4).

Therefore, the increase in the portion of the inactive Src-kinase at entering of inhibitor strength ened formation of the cell cytoskeleton, and the activity of its kinase domain is dispensable for this purpose. At the same time the part of the cells with processes among total of cells with tyrosinase activity compounded $30,6 \%$, and a portion of cells without processesrespectively $69,4 \%$ (in control 12,9 and $87,1 \%)$.

In the previous work we showed that during the daughter cell cytoskeleton formation the new portion of the inactive Src-kinase is allocated with exocytose bubbles from Golgi apparatus (Yavisheva et al., 2009).On centrosome membranes together with other proteins: PI3K and $\gamma$-tubulin, it forms large protein complexes. The Src-kinase is one of the key proteins participating in the formation of microtubules as performing 
protein cross-links, connects dimers of the tubulin in the uniform chain through its $\mathrm{SH} 2$ domains. Besides, the Src-kinase provides binding of a tubulin with membranes, and fixing of the ends of microtubules, because tubulin has no loci of linking with a membrane. But the Src-kinase has low affinity to a tubulin.

Therefore PI3K phosphorylates the tyrosine residues of tubulin, giving the chance of the $\mathrm{SrcSH} 2$ domains to join to the phosphotyrosine sites of a tubulin. And only after that there is an activization of the kinase lobe of Src. If in the moment of the microtubules formation the kinase lobe of Src was activated, it would reduce its affinity to tubulin in a bigger degree. In this case the Src-kinase would show first of all the kinase activity, but not the protein crosslinks. It would lead to falling of microtubules formation and decrease in cells differentiation, that is observed at viral carcinogenesis where $\mathrm{v}$-Src constantly has high kinase activity(Kaplan et al., 1994).

Interestingly, that almost in all the samples after the inhibitor entering there is a jump, i.e. the synchronous division of the elongated cells (fig. 5)

At the same time the quantity of the elongated cells decreased to $16,4 \%$ (in control $-25,1 \%$ ), and the number of round cells as a product of their division, increased to $10,6 \%$ (in control $-7,1 \%$ ). After that the population became monotonous, the average cell area increased in comparison with control that reduced cells density (fig. 3). Therefore, the inactive Src-kinase, participating in the cytoskeleton organization, synchronizes the cytokinesis. . However for further initiation of proliferation the active Src-kinase is essential, because it participates in phosphorylation of many proteins necessary for a mitosis. Really, at UV-radiation and in control gradual transition of reserve cells into the transitional and elongated cells was revealed, i.e. there was only a preparation for a mitosis (fig. 5).UV reduces a portion of the inactive Src-kinase, and increases of the active, therefore the proliferative activity of cells changes according to the dose of radiation. Hence, the activated Src, reacting to light, regulates the mitotic activity of cells in dependence of efficiency of the solar radiation including UV. Apparently, the Srckinase participates in organization of circadian and seasonal rhythms.

In conclusion, thus, the carried out research revealed that the most important functions of the cell - the cytoskeleton construction and, therefore, the differentiation, are carried out generally due to the inactive Src-kinase.

Table.1 The quantity of the cells with processes and total cells with tyrosinase activity after UV irradiation and inhibitor application

\begin{tabular}{|l|l|l|l|l|l|}
\hline \multirow{2}{*}{ types of cells } & \multicolumn{5}{|l|}{ average quantity of cells in one vision field } \\
\cline { 2 - 6 } & control & $\begin{array}{l}\mathrm{UV} \\
\text { minutes }\end{array}$ & $\begin{array}{l}\mathrm{UV} \\
\text { minutes }\end{array}$ & $\begin{array}{l}\mathrm{UV} \\
\text { minutes }\end{array}$ & inhibitor \\
\hline cells with processes & $0,95(0-2)$ & $\begin{array}{l}1,35(1-3) \\
\mathrm{P}<0,05\end{array}$ & $\begin{array}{l}0,4(0-1) \\
\mathrm{P}>0,05\end{array}$ & $\begin{array}{l}0,2(0-1) \\
\mathrm{P}>0,05\end{array}$ & $\begin{array}{l}2,6(1-4) \\
\mathrm{P}<0,05\end{array}$ \\
\hline $\begin{array}{l}\text { total cells with tyrosinase } \\
\text { activity }\end{array}$ & $7,35(6-8)$ & $\begin{array}{l}5,6(4-6) \\
\mathrm{P}<0,05\end{array}$ & $\begin{array}{l}4,3(3-5) \\
\mathrm{P}<0,05\end{array}$ & $\begin{array}{l}3,3(2-4) \\
\mathrm{P}<0,05\end{array}$ & $\begin{array}{l}8,5(7-10) \\
\mathrm{P}<0,05\end{array}$ \\
\hline
\end{tabular}

$\mathrm{P}$ in relation to control 
Fig.1 Dynamics in quantity change of cells with processes and total of cells with tyrosinase activity at UV-radiation

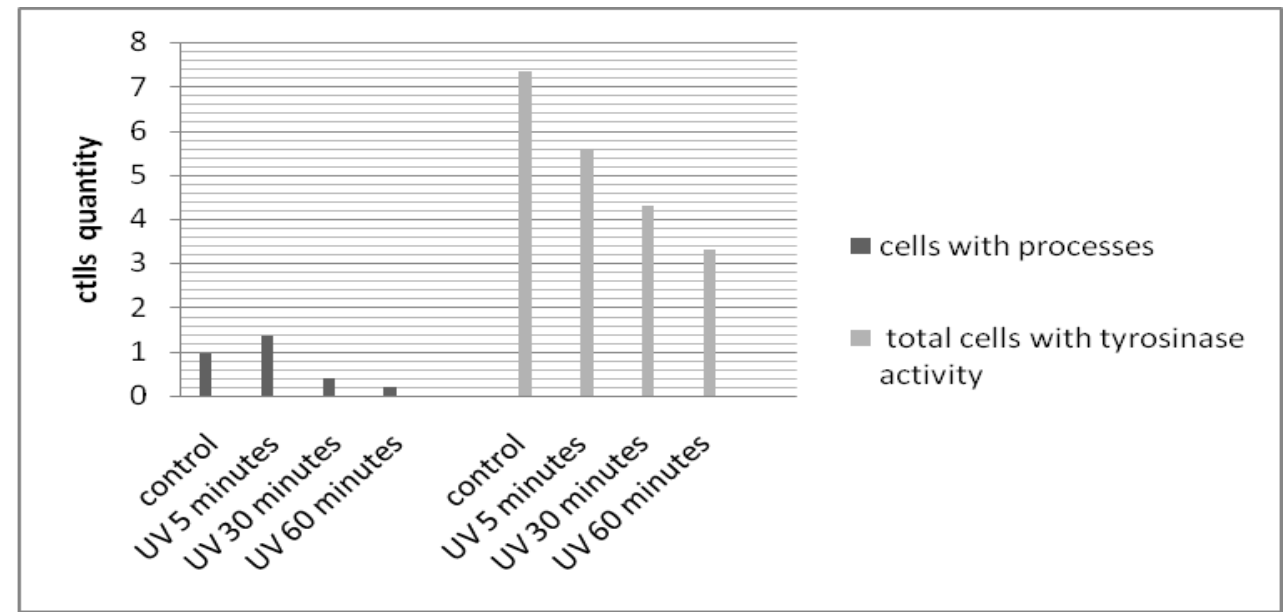

Fig.2 The quantitative characteristic of cells of a different form in control and at UV-radiation

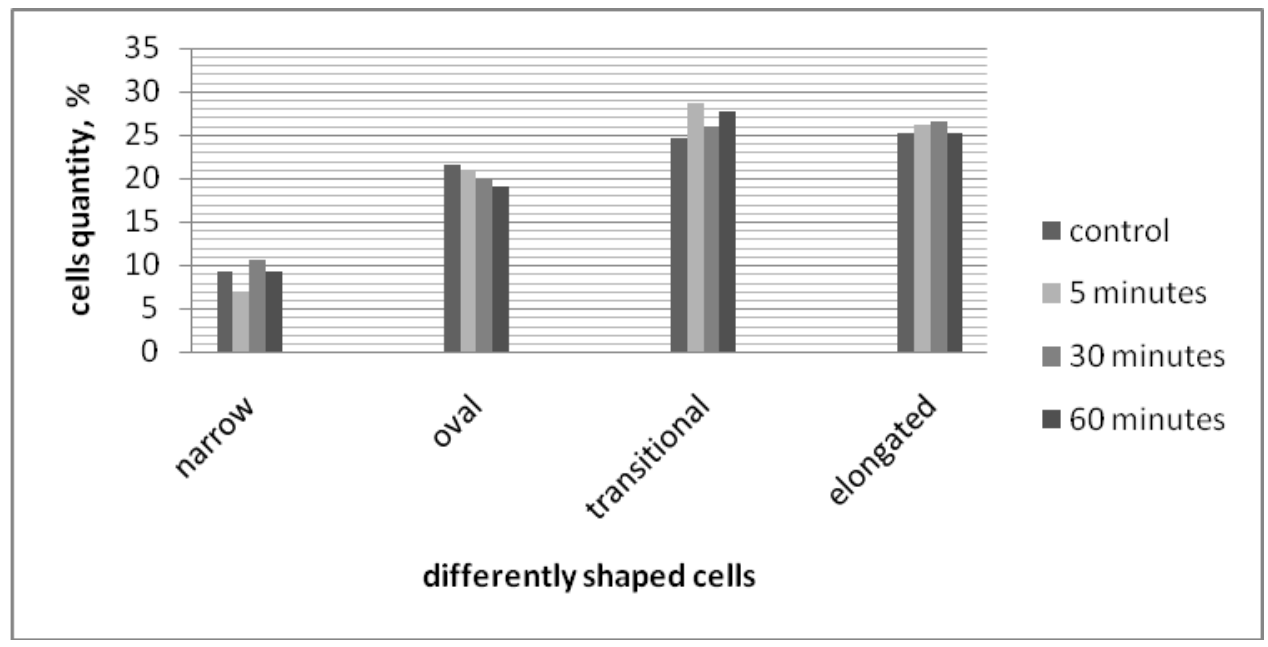

Fig.3 The fluctuations of cells area at UV-radiation and inhibitor in comparison with control

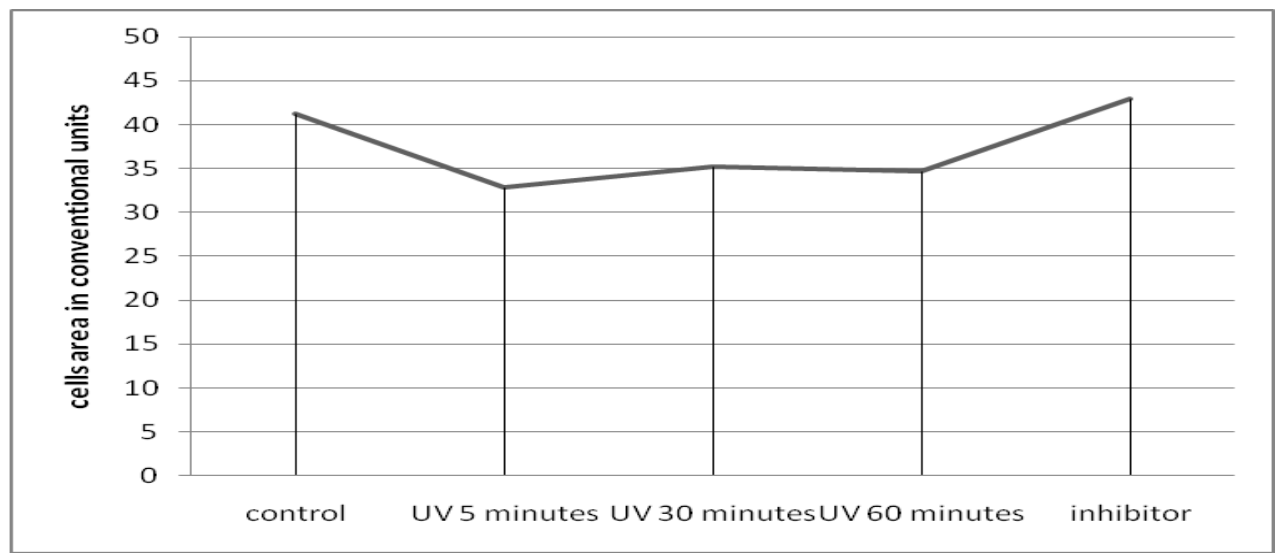


Fig.4 Change in quantity of cells with processes and total of cell with tyrosinase activity at entering of inhibitor in comparison with control

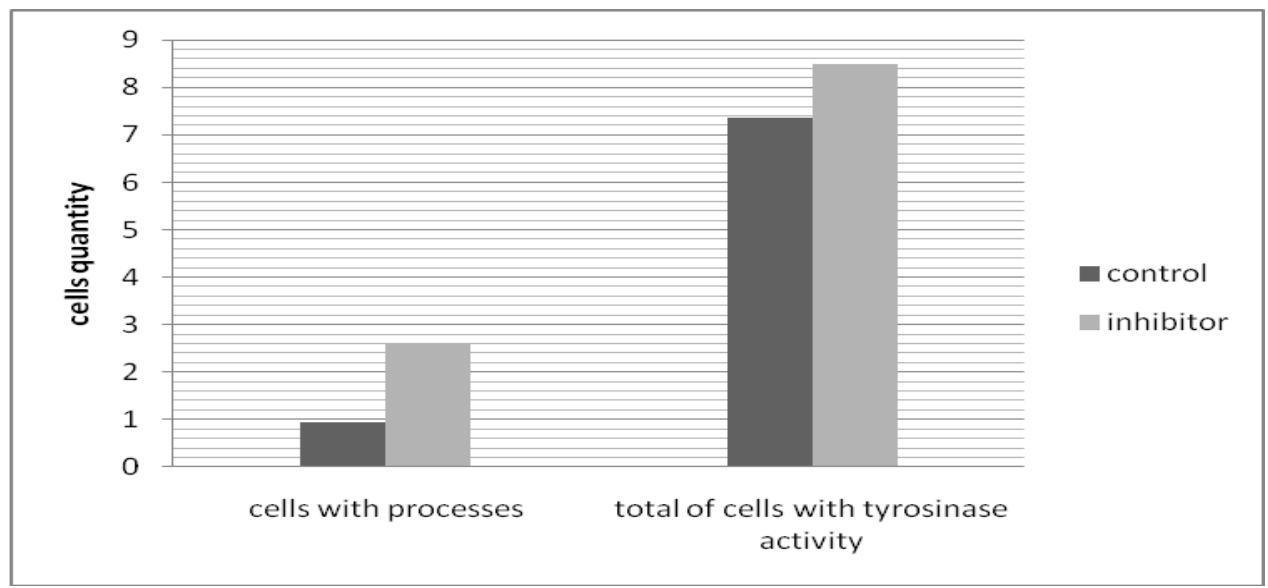

Fig.5 The quantitative characteristic of Hep2cells population after inhibitor entering and UVradiation..

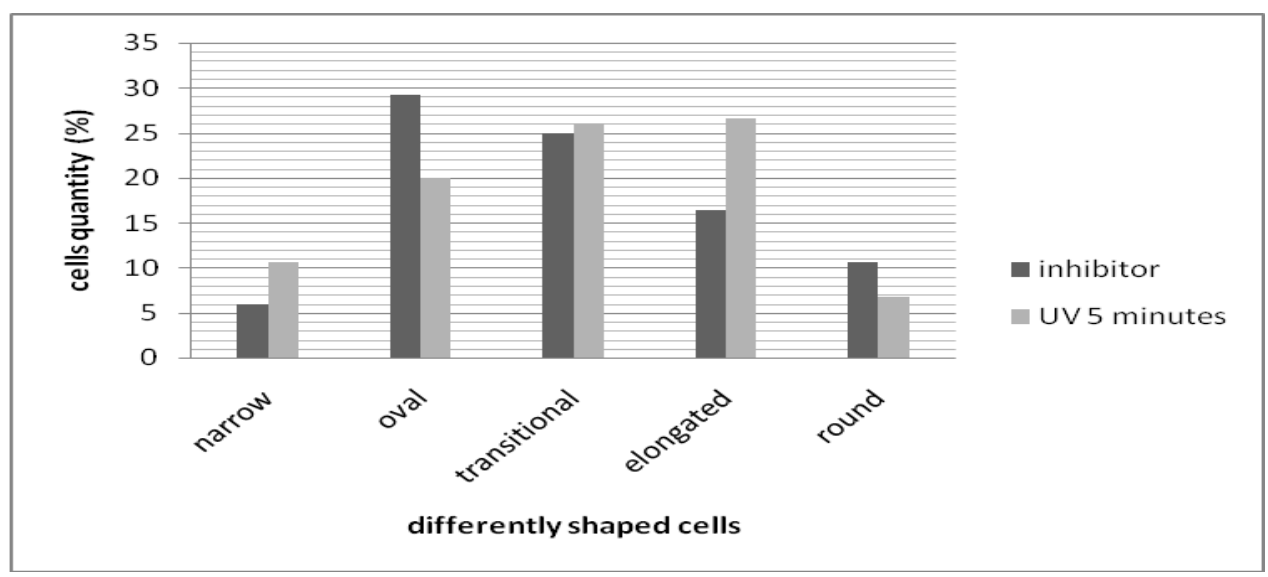

Besides the inactive Src-kinase is necessary for melanogenesis. Therefore when tyrosinase synthesis strengths, the portion ofthe inactive Src-kinase will decrease, therefore the formation of a cytoskeleton and a differentiation of cells will suffer.Decrease in a portion ofthe inactive Src-kinase at short UV-radiation generally depends on the UV oxidizing properties. It leads to short-term strengthening of cytoskeleton formation in cells, and then to reduction of proliferative activity of cambial cells which number falls, and to aggravation of cancer process.
During the increase of UV influence time, except an oxidative stress there is the activization of tyrosinase synthesis which reduces a part of the inactive Src-kinase in the cells even more, and thus indirectly competes with a cytoskeleton for the inactive Src-kinase. It leads to qualitatively new phenotype of population: the proliferative activity and malignancy of the cells sharply increase due to decrease of the maturing of cells; at the same time violations begin to be revealed in the earliest offspring of the cambial cells. 
The present study showed earlier that in the cancer development the decrease in cambial cells quantity to 6 in a morphofunctional zone plays the main role among the local factors. In the melanoma development the main starting moment is the hyperactivity of tyrosinase at normal quantity of cambial cells.

Apparently, the mechanism of sharp strengthening of tyrosinase synthesis at rather high dose of radiation leading to considerable decrease in the portion of the inactive Src-kinase in the cells and, therefore, violation of the differentiation can be considered as a key in melanoma development.

\section{References}

Aikawa, R., Komuro, I., Yamazaki, T., Zou Y., Kudoh S., Tanaka M., Shiojima I., Hiroi Y., Yazaki Y. 1997.Oxidative stress activates extracellular signalregulated kinases through $\mathrm{Src}$ and Ras in cultured cardiac myocytes of neonatal rats. J. Clin. Invest., 100(7), 1813-1821.

Arthur, W.T., Petch, L.A., Burridge, K. 2000. Integrin engagement suppres_sesRhoA activity via a c_Src_dependent mechanism. Curr. Biol., 10(12), 719-722.

Borshchevskaya, M.I., Vasil'eva, S.M. 1999. Development of ideas of melanin pigments biochemistry and pharmacology. Biomeditsinskaya himiya., 45(1), 13-23.

Breitenlechner, Ch.B., Kairies, N.A., Honold, K,. Scheiblich, S., Koll, H, Greite, E., Koch, S, Schafer, W., Huber, R., Engh, R.A. 2005. Crystal structures of active Src kinase domain complexes. JMB, 353(2): 222-231.

Brunton, V.G., MacPherson, I.R.., Frame, M.C. 2004. Cell adhesion receptors, tyrosine kinases and actin modulators: a complex three-way circuity. Biochim. Biophys. Acta, 1692(2-3), 121-144.

Burova, E.B., Gonchar, I.V., Nikolsky, N.N. 2003. Stat1 and stat3 activation by oxidative stress in A431 cells involves src-dependent EGF receptor tranactivation. Tsitologiya, 45(5), 466477.

Chentsov, Y.S. 2005. Introduction in the cellular biology (in Russian). Moscow «Akademkniga».

Devary, Y., Gottlieb, R.A., Smeal, T., Karin, M. 1992. The mammalian ultraviolet response is triggered by activation of Src tyrosine kinases. Cell, 71(7), 1081-1091.

Gubler, E.V., Genkin, A.A. 1973. Nonparametric criteria in medicalbiological researches. Meditcina.

Kaplan, K.B., Bibbibs, K.B., Swedlow, J.R., Arnaud, M., Morgan, D.O., Varmus, H.E. 1994. Association of the aninoterminal half of the c-SRC with focal adhesions alters their properties and is regulated by phosphorylation of tyrosine 527. The EMBO J., 13(20), 4745-4756.

Mallozzi, C., Di Stasi, M., Minetti, M. 2001. Peroxynitrite-dependent activation of src tyrosine kinases lyn and hck in erithrocytes is under mechanistically different pathways of redox control, Free Radical Biol. Med., 30(10),11081117.

NetrunenkoI, Yu., Ignatiev, D.V. 2007. Hyperpigmentation: the problems and the ways of their solution. Dermatologiya. Prilozhenie k zhurnalu Consilium Medicum, 2, 50-57.

Riley, P.A. 1993. Mechanistic aspects of the control of tyrosinase activity, Pigment cell Res., 6: 182-185.

Sichun Yang, Benoit Roux. 2008. Src kinase conformational activation: 
thermodynamics, pathways, and mechanisms. Plos Comput. Biol., 4(3): e1000047.

Yavisheva, T.M., Shcherbakov, S.D. 2009. Characteristic features of proliferation and differentiation of cambial and daughter cells in morphofunctional zones in normal epithelium and cancer in age aspect. UspekhiGerontologii, 22(4): 605-613.

Yavisheva, T.M., Shcherbakov, S.D. 2013. Epithelial-stromal morphofunctional zones: structure and functions (in Russian), Moscow.

Yavisheva, T.M., Shcherbakov, S.D. 2014. Melanoma and cancer development in patients from 20 to 60 years old with normal cambial cells quantity in morphofunctional zones. Uspekhi Gerontologii, 27(4): 753-757.

Yavisheva, T.M., Shcherbakov, S.D., Golubeva, I.S., Sharafutdinov, G.Z. 2007. Interaction of cambial dermal cells (fibroblasts) and epidermis in morphofunctional zone of mouse skin. Byulleten Eksperimentalnoi Biologii I Meditsiny, 144(11): 594-599.

Yavisheva, T.M., Shcherbakov, S.D., Golubeva, S., Savluchinskaya, L.A., Rizhova, N.I. 2012. The relationship between the epidermal melanocytes, Langerhans cells and epidermal cambial cells. Byulleten Eksperimentalnoi Biologii I Meditsiny, 153(3): 346-349.

Yavisheva, T.M., Shcherbakov, S.D., Sharafutdinov, G.Z. 2005. On epithelial cell differentiation in the system of tissue units.//Doklady. Biol. Sci., 401(6): 833-836.

Yavisheva, T.M., Yagubov, A.S. 1996 Quantitative morphology of cells of the basal layer of the multilayered mouse cornea epithelium and human lung cancer. Ontogenez., 27(2): 95-99.

\section{How to cite this article:}

Tatiana Yavisheva and Sergey Shcherbakov. 2016. Participation of an Inactive and Active Srckinase in Formation of a Cytoskeleton and Melanogenesis in Hep2 Cells. Int.J.Curr.Microbiol.App.Sci. 5(12): 583-593. doi: http://dx.doi.org/10.20546/ijcmas.2016.512.063 